\title{
Sistem Peringatan Dini Bencana Tsunami Menggunakan Logika Fuzzy
}

\author{
Meira Parma Dewi \\ Jurusan Matematika Universitas Negeri Padang \\ e-mail:_meiradaud@gmail.com
}

\begin{abstract}
This research aimed to analyses the probability of an earthquake occurring potential to cause a Tsunami. The Tsunami wave may occur if the earthquake become in ocean, which is called tectonic earthquake. Tectonic earthquake caused of several thingst on the ocean e.g. volcanoes, avalanches, and the movement of earth's plates. Fuzzy logic were used to observed that the earthquakes have Tsunami potential cause or not. There are two of input variable that implement in fuzzy logic, both are the strange of earthquake and the distance of earth's plates movement. Tsunami potential cause is set as the output variable. We will know that the earthquake will cause the Tsunami earlier so we can manage the prevention measures.
\end{abstract}

Keyword: Earthquake, Tsunami, Fuzzy Logic

\section{PENDAHULUAN}

Wilayah Negara Indonesia merupakan salah satu Negara yang rentan dan sering mengalami gempa bumi. Gempa bumi merupakan peristiwa alam yang tidak dapat diperiksi atau diperkirakan kapan dan bagaimana datangnya. Gempa bumi dapat terjadi karena aktivitas gunung berapi (vulkanik) dan dapat juga terjadi karena pergerakan lempeng bumi di dasar laut (tektonik). Gempa bumi yang terjadi dengan skala kecil dan sedang biasanya tidak menimbulkan dampak besar, namun jika gempa yang tejadi dalam skala besar dapat menimbulkan dampak yang cukup besar seperti runtuhnya bangunan, rusaknya jalan raya dan jembatan bahkan menimbulkan Tsunami.

Tsunami merupakan gelombang laut yang besar yang terjadi akibatnya adanya pergerakan pada patahan lempeng bumi didasar laut. Sebelumnya sebagian besar masyarakat Indonesia tidak mengetahui Tsunami hingga akhir Desember 2003 Tsunami menerjang Nanggro Aceh Darusslama (NAD) dan menimbulkan korban jiwa yang sangat banyak. Kejadian ini menimbulkan trauma pada masysrakat tidak hanya masyarakat NAD tetapi juga masyarakat Indonesia lainnya.

Pada umumnya masyarakat awam tidak dapat mengetahui jenis gempa yang terjadi (vulkanik/tektonik) sebelum ada informasi dari BMKG. Sehingga jika gempa itu terjadi selalu ada ketakutan bahwa gempa itu akan diiiringi oleh gelombang Tsunami. Jika ketakutan itu hanya sekedar ketakutan yang jika tidak terbukti kemudian mungkin tidak masalah. Namun sangat memprihatinkan jika ketakutan itu justru menimbulkan korban jiwa. Karena takut akan Tsunami, banyak orang yang lari dengan maksud menyelamatkan diri justru menjadi korban kecelakaan. Sehingga sangat diperlukan suatu Sistem terintegrasi yang dapat memberikan informasi kepada masyarakat apakah gempa yang terjadi berpotensi menimbulkan Tsunami atau tidak. 
Gelombang Tsunami dapat terjadi jika gempa bumi bersal dari pergerakan vertikal dari lempengan bumi. Pergerakan lempengan bumi tersebut bersifat seperti pegas yang dapat kembali ke posisi semula. Jika patahan cukup jauh kemudian kembali ke posisi semula maka patahan tersebut akan mendorong air laut ke atas hingga berkali-kali sampai patahan tersebut kembali ke posisi semula.

Untuk dapat memprediksi apakah gempa bumi yang terjadi akan menimbulkan bencana Tsunami atau tidak maka dilakukan penelitian dengan judul system peringatan dini Tsunami menggunakan logika Fuzzy.

\section{METODE}

Pada penelitian ini digunakan logika Fuzzy sebagai aplikasi dalam menyelesaikan masalah. Terdapat dua variabel yang digunakan, yaitu kekuatan gempa dan jarak pergerakan vertikal lempengan bumi. Kekuatan gempa dibagi atas 3 yaitu tidak kuat(TK), kuat (K) dan sangat kuat (SK). Jarak pergerakan vertikal lempengan bumi juga dibagi menjadi 3 yaitu tidak jauh (TJ), jauh (J) dan sangat jauh $(\mathrm{SJ})$.

Jika terjadi gempa tektonik maka kekuatan gempa akan diukur dan menghasilkan kekuatan gempa dalam skala Richer (SR). Alat sensor yang dipasang didaerah pantai akan mengukur jarak patahan pergerakan lempengan bumi. Kekuatan gempa (SR) dan jarak patahan (Meter) dikirim ke sistem. Kemudian diproses dan menghasilkan suatu kesimpulan apakah gempa berpotensi menimbulkan Tsunami atau tidak.

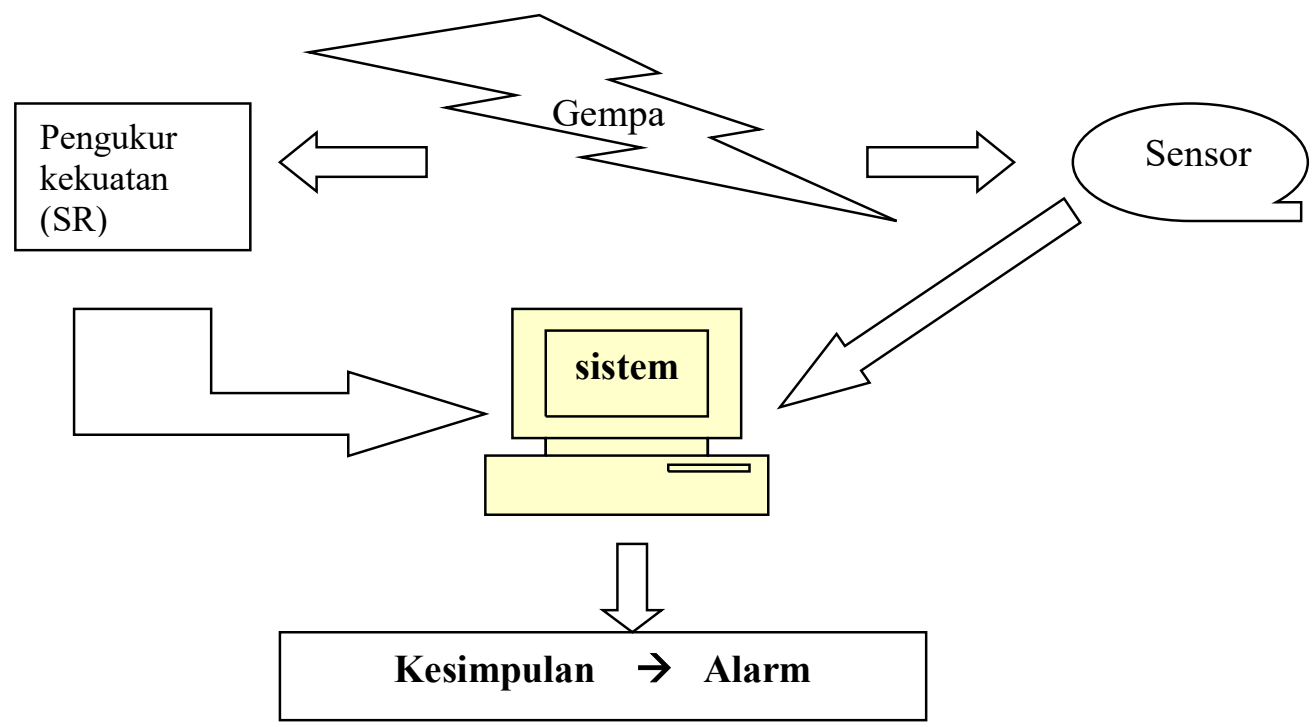

Gambar 1. Rancangan Sistem Peringatan Dini Tsunami

Dari variabel-variabel yang dibentuk diperoleh membership function sebagai berikut : 


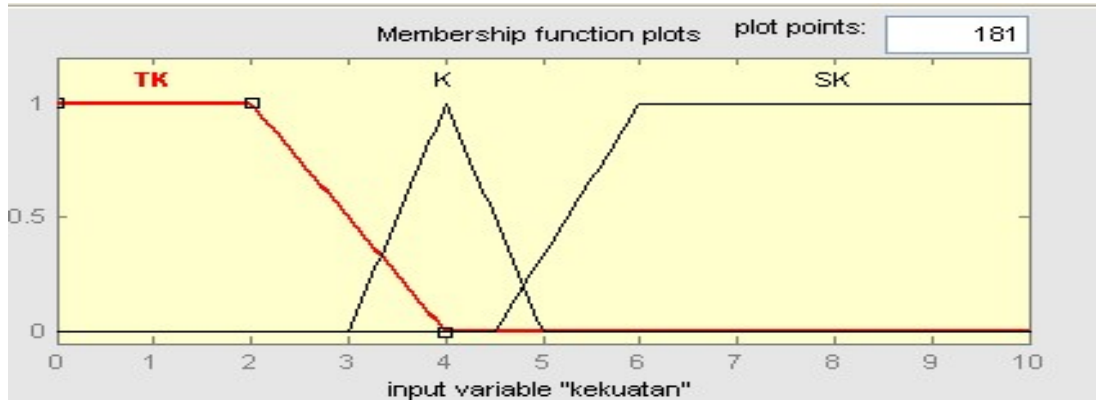

Gambar 2. Membership Function Variabel Kekuatan Gempa

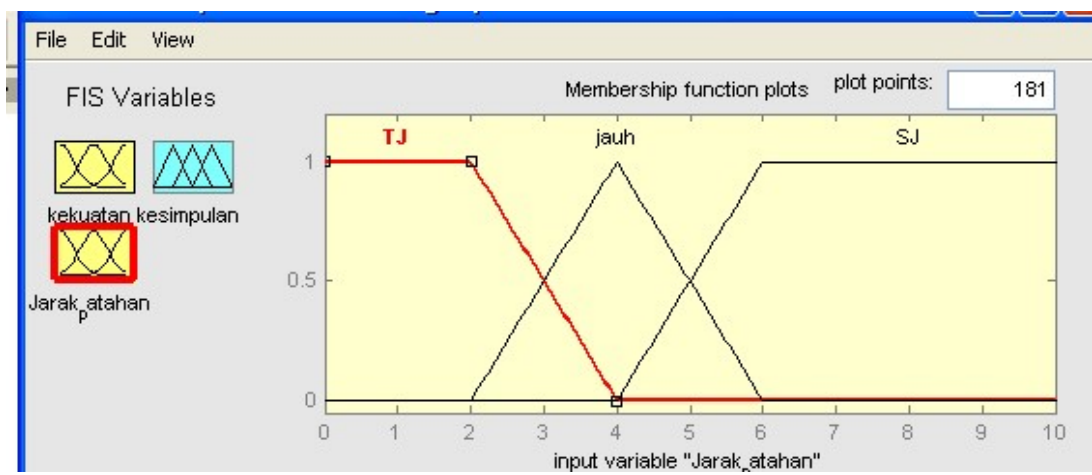

Gambar 3. Membership Function Variabel Jarak Pergerakan Lempeng Bumi

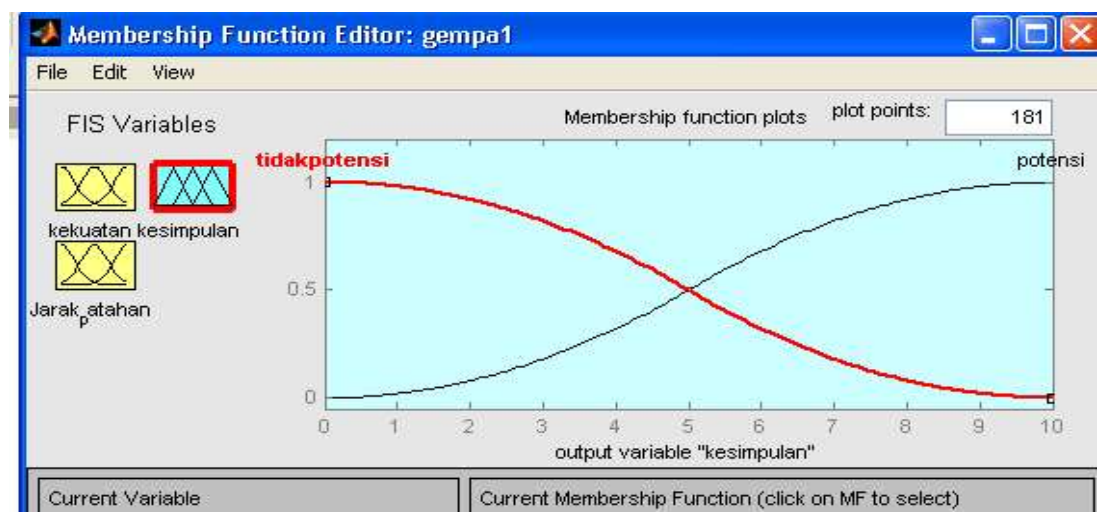

Gambar 4. Membership Function Variabel Output

\section{HASIL DAN PEMBAHASAN}

Dari percobaan yang dilakukan terhadap membership function yang dirancang maka diperoleh inference rule sebagai berikut :

1. Jika kekuatan $=\mathrm{TK}$ dan $\mathrm{jarak}=\mathrm{TJ}$ maka kesimpulan $=$ tidak berpotensi 
2. Jika kekuatan $=\mathrm{TK}$ dan jarak $=\mathrm{J}$ maka kesimpulan $=$ tidak berpotensi

3. Jika kekuatan $=\mathrm{K}$ dan jarak $=\mathrm{TJ}$ maka kesimpulan $=$ tidak berpotensi

4. Jika kekuatan $=\mathrm{K}$ dan jarak $=\mathrm{J}$ maka kesimpulan $=$ berpotensi

5. Jika kekuatan $=\mathrm{K}$ dan jarak $=\mathrm{SJ}$ maka kesimpulan $=$ berpotensi

6. Jika kekuatan $=\mathrm{SK}$ dan jarak $=\mathrm{TJ}$ maka kesimpulan $=$ tidak berpotensi

7. Jika kekuatan $=\mathrm{SK}$ dan jarak $=\mathrm{J}$ maka kesimpulan $=$ berpotensi

8. Jika kekuatan $=\mathrm{SK}$ dan jarak $=\mathrm{SJ}$ maka kesimpulan $=$ berpotensi

Gempa bumi yang terjadi tidak akan berpotensi menimbulkan Tsunami apabila memenuhi salah satu dari kejadian berikut (1) gempa tersebut berkekuatan tidak kuat atau kuat dan jarak pergerakan lempeng bumi tidak jauh; (2) gempa bumi berkekuatan sangat kuat dan jarak pergerakan lempeng bumi tidak jauh. Sedangkan gempa bumi yang berpotensi menimbulkan Tsunami adalah gempa bumi yang berkekuatan kuat atau sangat kuat dengan jarak pergerakan lempeng bumi jauh atau sangat jauh.

Pada inference rules diatas tidak digambarkan jika kekuatan gempa tidak kuat (TK) tetapi jarak patahan sangat jauh (SJ), karena gempa tektonik yang terjadi akibat adanya patahan lempeng bumi yang jauh akan menimbulkan getaran yang kuat.

\section{KESIMPULAN}

Sistem peringatan dini bencana Tsunami merupakan sistem yang bekerja dengan dukungan dari beberapa sistem lainnya. Sangat diperlukan adanya integritas agar informasi yang diperoleh tepat dan akurat. Disamping adanya system ini diharapkan masyarakat lebih bijak dalam menghadapi bencana dan diharapkan adanya suatu sistem penanganan terpadu jika terjadi bencana gempa seperti pelatihan dan penyuluhan yang diberikan kepada masyarakat.

\section{DAFTAR PUSTAKA}

1. Irjaya Desmonda, Niko.Pamungkas,Adjie. (2014). Penentuan Zona Kerentanan Gempa Bumi Tektonik Di Kabupaten Malang Wilayah Selatan. Jurnal Teknik PomitsVol.3 No.2 ISSN 2337-3539.

2. Kusumadewi,Sri. Purnomo,Hari. (2004). Aplikasi Logika Fuzzy Untuk Pendukung Keputusan. Graha Ilmu. Yogyakarta.

3. Mustofa Nur,Arif. (2010). Gempa Bumi, Tsunami dan Mitigasinya. Jurnal Geografi Vol. 7 No.1. ISSN. 2085-191X

4. Yasir Baeda, Ahmad. Husain,Firman. (2012). Kajian Potensi Tsunami Akibat Gempa Bumi Bawah Laut di Perairan Pulau Sulawesi. Jurnal Teoretis dan Terapan Bidang Rekayasa Sipil Vol 19 No 1 ISSN 0853-2982 